\title{
Is Cervical Cancer a Defeated Enemy?
}

\author{
Döbrössy L \\ Office of Chef Medical Officer, Budapest, Hungary
}

*Correspondence to: Döbrőssy L. MD, PhD. Albert Flóriánút 2-6., Budapest H-1097. Hungary; Tel: + 36305360375 ; E-mail: dobrossy.lajos@oth.antsz.hu

Received: June 07, 2018; Accepted: June 21, 2018; Published: June 24, 2018;

\section{Editorial}

Cervical screening by Pap-test has been on the top of public health agenda for several decades. This is not because of the epidemiological weight of the disease but because we have all tools for its prevention in hand. The primary prevention of cervical cancer by vaccination against human papillomvirus (HPV) infection is an increasingly widespread practice; however, we still do not know enough how long the protection will last. The secondary prevention by method of proven effectiveness for early detection of both premalignant lesion of uterine cervix, and cervical cancer itself has long been widely available for women. Screening tests, by definition, sort out apparently well persons who probably have the target disease those who have not. Cervical screening is to substantially reduce the burden of disease in terms of mortality, morbidity, and improve quality of life. Primary and secondary prevention of cervical cancer could be the "success story" of health care system. Unfortunately, they are not so.

In the last 50-60 years, the clinical spread of screening was followed by the need for its public health application. In 1960's, expert groups established the concept of "organized screening", as opposed to "opportunistic" one, meaning actions initiated and financed by the provider health care system, and individually inviting of those women to be screened [1]. In the development of such population screening, the Nordic Countries have shown a good example [2]. Population screening is most effective if most invited women in the eligible population choose to participate. The participation rate is the Achiles'heel of population screening.

In fact, not everyone benefits equally from the screening due to inequalities of various kind, such as diversity in health care systems, access to screening services, socioeconomic and demographic status, lack of knowledge and education, and last but not least, due to differences in geopolitical status [3]. Screening programmes are much better developed in Nordic and Western Europe as compared to the Central-Eastern Europe, where the burden of the disease is much higher due to a history of mostly opportunistic cervical screening practices, and due to the strong influence of political and economic changes in post-communist transition; as a result the screening facilities are underdeveloped [4].

As far as Europe is concerned, in 2003, the Council of the European Union recommended to its Member States to implement organized, population-based cervical screening programmes [5].
In 2017, in the second report of the implementation of the Council Recommendation, out of 27 member states not more than nine countries reported "complete rolling out", the rest of the countries "piloting" or "planning" organised cervical screening programmes [6]. The up-to-date estimates of cancer burden in Europe shows that cervical cancer mortality is inversely proportional to the intensity of the cancer screening activities in the respective countries [7].

The gynaecological community has a lot to contribute with to the impact of cervical screening, as the smear-taking for cytological analysis is their task in all those countries where the task is not delegated to paramedical personnel, as midwifes, praxis nurses, public health nurses. In such a situation, the gynaecologists are the "gatekeepers" of the screening which tends to be opportunistic rather than organized one; opportunistic screening is much less effective than the organized one [8]. The insistence of gynaecological community on their "historical role" seems to be a major obstacle to be overcome.

Cytological screening every three to five years can potentially prevent up to four out five cases of cervical cancer, and can reduce cervical cancer incidence up to $80 \%$ at population level [9]. Such benefits can only be achieved if screening is provided in organised population-based programmes with optimal attendance rate, and quality assurance at all levels [10]. Following this protocol, the cervical cancer might become a defeated enemy [11].

\section{References}

1. Hakama M, Niller AB, Day NE. (eds) Screening for Cancer of Uterine Cervix. IARC Sci. Publ. No. 76. IARC. Lyon. 1986. pp. 289-290.

2. Lärä E, Day NE, Hakama M. Trends in mortality from cervical cancer in the Nordic countries: association with organized screening programmes. Lancet i. 1247-1249. 1987.

3. Döbrőssy L, Kovács A, Budai A. Inequalities in cervical screening practices in Europe. Diversity. Equality Health Care 12(2): 34-36. 2015.

4. Maver P, Seme K, Korac T. et al. Cervical cancer screening practices in central and eastern Europe. Acta Dermatovenerol. 22: 7-19. 2013.

5. Council of the European Union. Council recommendation of 2 December on Cancer Screening. (2003/878/EC). Off. J. Eur. Union L327: 34-38.

6. Cancer screening in the European Union. Report on the implementation of the Council Recommendation on cancer screening. IARC. Lyon. 2017.

7. Vicus D, Sutradhar R, Lu Y. et al. on behalf of the Investigators of the Ontario Cancer Screening Research Network. The association between cervical cancer screening and mortality from cervical cancer: A population based case-control study. Gynecol. Oncol. 133 (2): 167-171. 2014.

8. Makkonen P, Heinävaara S, Tytti Sarkeala, Anttila A. Impact of organized and opportunistic Pap testing on the risk of cervical cancer in young women. A casecontrol study from Finland. Gynecol Oncol. 147: 601-606. 2017.

9. International Agency for Research on Cancer. Cervical cancer screening. Handbook of Cancer Prevention. IARC Press. Lyon. 2005. 
Döbrössy L (2018) Is Cervical Cancer a Defeated Enemy?

10. Arbyn M, Anttila A, Jordan J. et al European Guidelines for Quality Assurance in Cervical Cancer Screening. Second Edition. Summary Document. Ann Oncol. 21(3): 448-458. 2010
11. Peto J, Gilham C, Fletche O. et al The cervical cancer epidemic that screening has prevented in the UK. Lancet 364: 249-256. 2004. [crossref]

Citation:

Döbrössy L (2018) Is Cervical Cancer a Defeated Enemy?. Integr Gyn Obstet J Volume 1(1): 1-2. DOI: 10.31038/IGOJ.2018105 